\title{
Revista
}

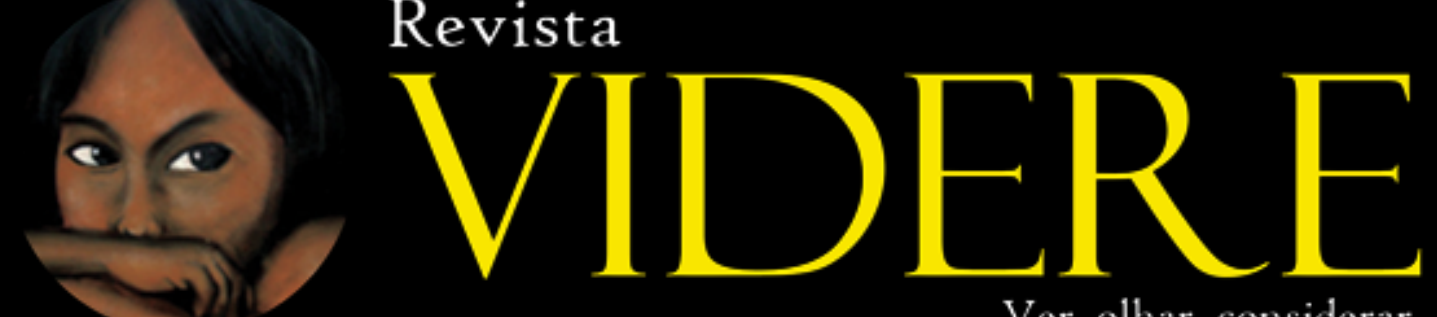

Ver, olhar, considerar.

\section{Resenha do livro "Reinventando os direitos humanos a partir do sul: Herrera Flores e a crítica descolonial"1 d}

\author{
Daniel Carneiro Leão Romaguera \\ Doutorando em Direito (PUC-RJ/PARIS-QUEST) \\ Pontifícia Universidade Católica do Rio de Janeiro (PUC-RJ) \\ Rio de Janeiro, Rio de Janeiro, Brasil \\ E-mail: danielromaguera@hotmail.com
}

Data de recebimento: 02/07/2019

Data de aprovação: 02/04/2020

\section{Apresentação}

Esse texto consiste em resenha do livro "Reinventando os direitos humanos a partir do sul: Herrera Flores e a crítica descolonial" de Natália Castilho. O livro é resultado da pesquisa de mestrado realizada no Programa de Pós-graduação em Direito da Unisinos (2014), sob a orientação de Fernanda Frizzo Bragato.

Como o título já revela, a proposta da autora é pensar os Direitos Humanos a partir do Sul, conforme relaciona a teoria crítica de Joaquín Herrera Flores e a perspectiva descolonial. Por um lado, traz à tona todo um debate descolonial sobre os Direitos Humanos na América Latina, abrangendo temas como colonialide, modernidade, pluralidade, etc. De outro, é feita leitura dos escritos de Herrera Flores, com ênfase na concepção materialista da dignidade da pessoa humana e na dimensão cultural dos Direitos Humanos, que são entendidos como processos de luta social.

O texto se divide em quatro partes, a saber: "As Contradições do Individualismo Liberal para Pensar os Direitos Humanos na América Latina"; "Pensamento Descolonial: a Modernidade como Mito"; "Pensamento Crítico dos Direitos Humanos e a Obra de Joaquín Herrera Flores: Primeiras Aproximações"; e "Chaves Contextuais e Conceituais: Um Conceito Não Absolutista e Não Colonialista de Direitos Humanos é Possível?". Além de contar com o prefácio de Fernanda Frizzo Bragato e a apresentação de José-Manuel Barreto.

${ }^{1}$ CASTILHO, Natália M. Reinventando os direitos humanos a partir do sul: Herrera Flores e a crítica descolonial. 1. ed. Rio de Janeiro: Lumen Juris, 2018. 208p. 
O livro, com efeito, compreende introdução à perspectiva descolonial, seguida de uma análise do estado da arte dos estudos descoloniais, também, de investigação crítica do pensamento liberal e da construção histórico-ocidental dos Direitos Humanos. Após, Natália apresenta a teoria crítica dos Direitos Humanos de Joaquín Herrera Flores, e, ainda, vislumbra alternativa aos Direitos Humanos na atualidade.

Já na introdução do livro, Natália Castilho situa a dimensão paradoxal dos Direitos Humanos, ao considerar a importância desses direitos para a concretização de avanços sociais e dos sistemas políticos democráticos, mas, também, destaca sua funcionalidade moderna e papel decisivo para a geopolítica internacional e práticas imperialistas. No cenário político atual, os Direitos Humanos não se realizam sem contradições, em especial, nos países periféricos, como àqueles da América Latina.

A autora, então, questiona as tensões dos Direitos Humanos diante da expansão e universalização do discurso ocidental, caracterizadas pelo projeto da Modernidade e os processos de globalização econômicaneoliberal. Em sentido contrário, trabalha o ímpeto emancipatório dos Direitos Humanos

Natália parte de referenciais críticos aos marcos hegemônicos, especialmente, ao discurso liberal moderno europeu de fundamentação dos Direitos Humanos. Por um lado, apresenta crítica à historicidade marcadamente etnocêntrica, de outro, busca resgatar e mobilizar resistências encobertas e silenciadas pelo discurso civilizatório da Modernidade ocidental.

Nesse sentido, constrói uma fundamentação descolonial para os Direitos Humanos associada às reflexões de Joaquín Herrera Flores, destacando-se a crítica à colonialidade/modernidade e a defesa da afirmação intercultural desses direitos no contexto latino-americano.

\section{Modernidade, Colonialidade e Direitos Humanos}

O livro começa pela crítica à teoria eurocêntrica dos Direitos Humanos, que é fundada na Modernidade. À qual, necessário pontuar, Natália entende como inserida em período histórico e contexto social específicos, caracterizados pelo desenvolvimento e triunfo da Europa colonial.

Significa dizer, a análise feita não considera a modernidade como toda e qualquer "modernidade", do modo como têm feito as grandes narrativas da história com " $\mathrm{h}$ " maiúsculo, ou o senso comum acadêmico, mas compreende por perspectiva Moderna àquela que se fez como totalidade pela subjugação do outro e pela afirmação da matriz colonial.

Assim, a autora identifica a Modernidade como produtora de hegemonias, com a imposição políticosocial e a construção de saber-histórico dominante. E, dentre as principais categorias que nortearam esse paradigma Moderno, destaca a do sujeito moderno, por entender determinante para a formação dos Direitos Humanos na perspectiva eurocêntrica².

\footnotetext{
${ }^{2}$ Natália explica: "O termo eurocêntrico não se refere a uma localização geográfica, e sim à noção geopolítica que também pode ser denominada como Norte global (CONNELL, 2011, p. 10). Ou seja, os parâmetros de análise e de teorização hegemônicos não se manifestam a partir das fronteiras do território do continente Europeu, mas sim da expansão das fronteiras do capital e de seus principais centros de poder. Segundo Barreto (2012, p. 19) o termo Europa também pode significar Ocidente, e pode igualmente exemplificar a posição dos Estados Unidos, da Austrália e do Japão, devido à radicalização do processo de industrialização de suas culturas e sociedades, que alcançaram um nível avançado de modernização. Ainda, retoma-se a formulação de Ruy Mauro Marini, um dos principais teóricos da Teoria da Dependência, segundo a qual a integração imperialista dos sistemas de produção promove o surgimento de novas regiões produtoras (impulsionadas pelo imperialismo) também na América Latina, o que reduz as
} 
O sujeito moderno, por sua vez, é aquele fundado sob o individualismo, quando do abandono da metafísica clássica e do surgimento do jusnaturalismo racionalista. Natália destaca o papel de Descartes e Kant (p. 20 e seguintes).

Isso não significa apenas que o pensamento mudou nessa época, mas que toda a construção social passa a ser centrada no "eu", ou seja, antropocêntrica. Afinal, o iluminismo insurge com essa tomada do indivíduo enquanto fundamento último e unidade básica da análise política e social (p. 24).

O indivíduo, como independe e autônomo, se relaciona com o próprio desenvolvimento europeu:

A consolidação das categorias individualidade, subjetividade, liberdade, autonomia e livre-arbítrio no campo filosófico - no decorrer dos séculos XVII e XVIII - acompanhou efetivamente o processo de transposição de modos de produção diversos na sociedade europeia: do sistema feudal ao capitalismo comercial, a partir da conquista da América e da exploração colonial ( $p$. 18).

Com isso, é definido o marco para toda a história mundial pelo esclarecimento do homem europeu, conforme a tradição filosófica e política reflete o liberalismo econômico e político moderno. Em especial, Natália destaca a formação dos Estados-Nação e os contornos de cidadania, como espaço prioritário do progresso e da civilização. Ao mesmo tempo, menciona as declarações de direitos, notadamente, a Constituição dos Estados Unidos da América e a Declaração de Direitos do Homem e do Cidadão, relacionadas ao liberalismo e ao surgimento da burguesia.

Tudo isso pode ser associado à construção de um espaço-tempo Moderno, que é europeu, mas também universal. No sentido de uma visão que se pretende universal e é capaz de se expandir, muitas vezes, de forma impositiva, sobre as diversificadas realidades e sociedades ao redor do mundo.

Nesse cenário, Natália analisa a formação do discurso hegemônico dos Direitos Humanos, evidenciando as propostas do individualismo liberal e os efeitos do eurocêntrico. É pelo universalismo europeu, então, que se tentou limitar os Direitos Humanos ao contexto apresentado, e, igualmente, eternizá-los ${ }^{3}$.

Afinal, a concepção prevalente dos Direitos Humanos reflete uma perspectiva histórica e geográfica bem localizada, enquanto se apresenta como objetiva e universal. Diante disso, a autora destaca a crítica descolonial dos Direitos Humanos ${ }^{4}$.

possibilidades de comércio e termos de troca equilibrados entre os países periféricos. Nesse contexto insere-se o conceito de subimperialismo, capaz de explicitar o caráter imperialista da economia brasileira em relação aos demais países latino-americanos, sobretudo porque a irracionalidade do desenvolvimento capitalista no Brasil traduz-se no estímulo da economia em direção ao exterior, no afã de compensar sua incapacidade de ampliar o mercado interno por meio da conquista de mercados já formados (MARINI, 2012, p. 156). Esse conceito permite, portanto, a adequação geopolítica e contextualizada do termo "eurocêntrico" para as análises realizadas no decorrer do trabalho" (p. 12).

3 “A teoria convencional dos direitos humanos é cotidianamente situada ou no contexto da história Europeia, ou em contexto nenhum. Quanto à primeira prática interpretativa, eventos isolados ou uma série de eventos podem ser trazidos à baila quando pensamento no horizonte horizontal no qual a teoria convencional de direitos humanos está localizada. Dentre os mais populares e influentes está o lluminismo, a 'história mundial' Hegeliana, o Holocausto e a sequência constituída pela Renascença, o Parlamento Inglês e a Revolução Francesa, como na construção de Habermas sobre os momentos cruciais da formação da subjetividade moderna na qual a história tem seu começo e significado na Europa e é realizada ali, enquanto eventos exteriores são considerados episódios menores ou simplesmente não são parte da história" (BARRETO, 2012, p. 8 apud p. 43, tradução livre).

4 "Enquanto a história dos direitos humanos na Modernidade é forjada, a historiografia desse percurso majoritariamente apresentada é única (BARRETO, 2012, p.19). Segundo Barreto, é comum encontrar a reiteração de uma linhagem formada por eventos chave, como a Magna Carta, a Revolução Britânica e o Bill of Rights, a Revolução de Independência Americana e a Declaração de Independência, a Revolução Francesa e a Declaração de direitos do homem, a crítica marxista e os direitos sociais proclamados na Constituição da União Soviética, o Holocausto e a Declaração Universal de Direitos Humanos, a emergência dos movimentos de direitos humanos nos anos 70, o final da Guerra Fria e, por fim, o 11 de setembro e a Guerra ao Terror. Nesse sentido, poderiam os direitos humanos existir além das ideias representadas e teorizadas a partir dessa história? E mais, poderiam representar 
Inicialmente, faz relato de algumas mobilizações do Sul que surgem para desafiar a predominância da razão eurocêntrica e do projeto moderno, em especial, na América Latina. Onde se destaca o descolonialismo, quando um grupo de teóricos latino-americanos, no final dos anos 90, se organiza e faz crítica da produção do conhecimento nas ciências humanas e sociais. Os pensadores descoloniais seguem o legado dos estudos pós-coloniais e da filosofia social latino-americana.

Natália apresenta a importância de pensar a partir do Sul, ao questionar as condições geopolíticas de construção do conhecimento e propor uma teoria crítica e descolonial dos Direitos Humanos, considerada a especificidade latino-americana. O que implica reconhecer a colonialidade como elemento central da modernidade, como sua face oculta, consequentemente, determinante à construção desses direitos.

A partir de conceitos como sistema-mundo, modernidade/colonialidade, centro/periferia, colonialidade do poder, etc., Natália investiga como a colonialidade se impõe pelas hierarquias sociais segundo a concepção evolutiva da história e do progresso ocidentais.

\section{A crítica descolonial dos Direitos Humanos}

Natália inicia com comentários sobre a tese de Dussel (2007) acerca da origem da modernidade no Séc. XVI, também, da análise de Barreto (2013) do direito natural na formação da lei internacional. Para Dussel (2013), o pensamento da expansão da Europa por um mundo colonial representa o início da filosofia política moderna. De outro lado, “(...) os princípios norteadores do direito natural estabeleceram as bases da lei internacional que surgia, a qual, em seu primeiro quadro, deveria ser entendida estritamente como a 'lei metropolitana", imperial, colonial e europeia"” (BARRETO, 2013, p. 189).

Barreto destaca a violência da conquista e o direito de intervir e dominar outros povos e territórios, a partir do debate entre Ginés de Sepúlveda (1498-1573) e Bartolomé de Las Casas (1484-1566), quando das propostas de solução do problema do novo continente e de ius gentium, e, também, a partir dos direitos das pessoas e das nações de Francisco de Vitoria (1483-1546) e Francisco Suárez (1548-1617) (p. 62).

Assim, se iniciou a construção do mito da modernidade pela consolidação da identidade europeia nesse período, enquanto o mundo foi reduzido a termos europeus, que, por sua vez, foram termos identificados como universais (FITZPATRICK, 2009).

O indivíduo europeu (heterossexual, proprietário, branco, etc.) se estabelece como o cerne da concepção de humano na Modernidade, em oposição aos desprovidos de humanidade (negro, índio, mulher, estrangeiro, etc. $)^{5}$. Tal divisão de mundo se afirma pelas diversas práticas de inferiorização, submissão e exclusão do outro, tanto no âmbito da construção do saber como do desenvolvimento político-social.

valores e ideais diferenciados a partir de outras histórias, das histórias não contatadas ou não reveladas pelo discurso tradicional da Modernidade, representado, conforme mostra Barreto (2012, p. 19-20)" (p. 37).

5 "São os povos e etnias transformadas no corpo "índio/a" e "negro/a", a exterioridade, que passam a representar, no discurso filosófico moderno, a partir da Conquista e da escravidão, papéis subalternos forjados pela própria retórica da Modernidade. O sistema jurídico operou a partir desse contexto, e forjou suas estruturas conceituais e teóricas de acordo com a lógica colonial” (p. 66). 
O que não acontece sem resistência e oposição, Natália remete a todo um cenário crítico ao eurocentrismo:

Segundo Barreto $(2012$, p.4) a crítica ao eurocentrismo possui antecedentes ao longo dos 500 anos de resistência ao imperialismo moderno. Especialmente a partir do século XX, vem sendo renovada e reforçada por diversas escolas de pensamento, dentre elas a Teoria Pós-colonial e o Orientalismo, os Estudos Subalternos, a Teoria Descolonial, os movimentos da Critical Race Theory e da Black Radical Theory, o Black Atlantic Studies e o Feminismo do Terceiro Mundo. Em relação aos possíveis antecedentes latino-americanos, para Enrique Dussel (2008, p. 342), remontam principalmente ao período pós-segunda guerra europeia e norte-americana, a partir da organização de um grupo de filósofos39 latino-americanos. Uma das principais fontes para a Teoria Descolonial, a Filosofia da Libertação, na década de 60 e 70, reflete uma teoria filosófica que busca contribuir com uma práxis da libertação. A Filosofia da Libertação entende que é preciso superar um dualismo simplista entre centro e periferia, exploradores versus explorados, sem cair em um discurso reacionário ou utópico. Nessa perspectiva, assume e fundamenta a existência da dominação, a partir de pressupostos e embasamento teóricos (DUSSEL, 2008, p. 343) (p. 75-76)

Natália conjuga alguns desses movimentos e faz crítica da construção moderna dos Direitos Humanos e sua fundamentação ${ }^{6}$, em oposição à centralização moral, à ontologia e ao dogmatismo da concepção prevalente desses direitos.

Diante do volume e da profundidade da obra, também, do propósito desta resenha, não é possível aprofundar cada contribuição de Natalia, apenas traço alguns pontos sobre a mobilização desde o sul dos Direitos Humanos.

A autora trata da latino-americanização dos Direitos Humanos que se dá pelo pluralismo jurídico não limitado ao reconhecimento da diversidade cultural, mas definido pela primazia da autodeterminação dos povos da América Latina frente ao conceito de Estado nacional. Isso pela necessidade de confrontar a totalidade moderna e deslocar o espaço habitual dos Direitos Humanos.

Os Direitos Humanos são colocados em questão a partir de processos históricos que refletem a disputa da consciência ético-política e a luta por reconhecimento da dignidade negada aos setores e movimentos sociais. Natalia entende, portanto, o mundo dos Direitos Humanos pela pluriversalidade de lutas e relatos de resistências diversificadas, enquanto experiências comuns possam conectar-se.

De um lado, fala da transmodernidade que pressupõe uma ética da libertação, pela qual, a alteridade pode superar a opressão a que os grupos subalternos foram sempre designados na ordem moderna/colonial. Isso implica transcender o monólogo imperial (DUSSEL, 1993). De outro, destaca o pensamento fronteiriço que contribui e fortalece formas de intercâmbio e diálogo intercultural, como instrumento fundamental do processo de desprendimento epistêmico (MIGNOLO, 2010).

\footnotetext{
${ }^{6}$ Com relação aos Direitos Humanos, segundo Rosillo Martínez (2011, p. 365), o dogmatismo pretende encontrar um fundamento absoluto para os direitos, como fosse uma razão evidente impossível de ser questionada. Essa postura gera atitudes intolerantes, que combinadas ao pensamento débil, tornam-se funcionais ao desenvolvimento neoliberal. Próprio da pós-modernidade ocidental, uma das propostas do pensamento débil é estabelecer vários fundamentos possíveis a partir dos quais se cai em um relativismo isento de quaisquer instâncias críticas ou de referências à realidade concreta dos sujeitos oprimidos. Ante à constatação de que todo fundamento gera totalitarismos, o pensamento débil acaba transformando os direitos humanos em valor de troca no mercado neoliberal. Quanto ao reducionismo, são posturas que enfocam suas análises somente nos elementos jurídicos, ou políticos, desconsiderando as demais dimensões dos direitos humanos. São as versões de juspositivismos, jusnaturalismos, historicismos e o monoculturalismo. O último problema da fundamentação hegemônica consiste no etnocentrismo, segundo o qual toda experiência de luta por dignidade humana e o uso de instituições jurídicas e políticas para protegê-la encontram-se exclusivamente em postulados Ocidentais (p. 46-47).
} 
O giro descolonial dos Direitos Humanos, portanto, se dá pela libertação radical e a descolonização epistemológica (p. 135).

\section{Joaquín Herrera Flores e os Direitos Humanos}

Diante dos pressupostos do pensamento descolonial dos Direitos Humanos, Natália situa o contexto teórico e epistemológico da obra de Herrera Flores, em especial, destaca a inversão ideológica dos Direitos Humanos e desenvolve sobre a noção desses direitos como produtos culturais.

A proposta da teoria crítica dos Direitos Humanos de Herrera Flores estabelece sua narrativa a partir dos sujeitos oprimidos e da crítica à dimensão colonialista da Modernidade, ao passo que expande o horizonte emancipatório desses direitos.

Natália (p. 133) diferencia tal percepção do projeto emancipatório moderno da Escola de Frankfurt, já que este não enfrenta os processos excludentes que o seu próprio desenvolvimento gerou, a herança colonial e suas consequências nefastas (genocídios, opressão, relativização da importância das vidas humanas) (MIGNOLO, 2010).

Herrera Floras concebe a noção sócio-histórica do direito em busca da emancipação humana, especialmente nas obras El proceso cultural: Materiales para la creatividad humana (2005a) e Los derechos humanos como productos culturales: Crítica del humanismo abstracto (2005b).

Natália (p. 40) sintetiza que os Direitos Humanos: “(...) como todo fenômeno jurídico e político, encontram-se permeados por interesses ideológicos, que não podem ser entendidos separadamente do contexto social e cultural no qual estão inseridos (HERRERA FLORES, 2000)" (p. 140). Nesse sentido, se opõe a compreensão dos Direitos Humanos como ideal, quando "(...) são pensados como produtos dados de antemão e sem qualquer relação com os conflitos sociais (HERRERA FLORES, 2009b, p. 79)".

Herrera Flores, então, propõe a reinvenção dos Direitos Humanos a partir da interculturalidade e dos processos de luta que buscam à proteção da dignidade humana pela garantia de condições materiais de produção e reprodução da vida. Isso pela inversão ideológica das possibilidades negativas do discurso liberal em favor das mobilizações de lutas emancipatórias dos Direitos Humanos.

A partir disso, se preocupa com os Direitos Humanos em direção às realidades periféricas, que incorpora tanto a crítica da ideologia neocolonialista como do sistema capitalista, tendo em vista a "(...) necessidade de criar de condições materiais de vida para todas as pessoas e povos, diante dos vastos e profundos processos de exclusão gerados pelo capitalismo tardio e globalizatório" (p. 151).

De tal modo, é possível olhar para o caráter pluriverso das sociedades latino-americanas, no sentido de uma proposta intercultural para os Direitos Humanos, e, assim, construir um pensamento crítico desses direitos assentado nas preocupações peculiares do contexto latino-americano (p. 134).

Natália realiza a aproximação da leitura de Joaquín Herrera Flores como uma proposta descolonial dos Direitos Humanos, ao caracterizar os principais aportes de sua teoria crítica e destaca sua recepção na América Latina. 


\section{Considerações finais}

O livro de Natália é um trabalho inédito e necessário sobre o pensamento descolonial e os Direitos Humanos no Brasil, cumprindo papel importante no que diz respeito ao engajamento político-social das pesquisas na área de direito. Ela tem o ímpeto de articular a teoria crítica dos Direitos Humanos e a perspectiva descolonial para enfrentar problemas sociais do direito.

Além disso, seu trabalho é preciso ao apresentar a teoria crítica de Joaquín Herrera Flores, aprofundando os argumentos do autor quando desafia os conceitos tradicionais do direito e do pensamento político ocidental ante a realidade latino-americana.

Importante destacar, também, alguns autores no Brasil que têm contribuído para a descolonização do direito com leituras críticas voltadas aos Direitos Humanos, como Fernanda Bragato, Cesar Augusto Baldi, Enzo Bello, Antonio Wolkmer, João Paulo Allain Teixeira, Thula Pires, Manuel Gándara.

Sobretudo, a contribuição da obra se dá tanto para a construção do pensamento descolonial do direito, conforme visão característica sobre os Direitos Humanos, como para enfrentar os desafios do contexto político atual. O livro, portanto, acrescenta com distinção reflexões à teoria crítica do direito e ao pensamento descolonial, por investigar temas tão caros como colonialidade, capitalismo, Direitos Humanos, modernidade, violência, etc.

\section{Referências}

BARRETO, José-Manuel (Ed). Human Rights from a Third World Perspective: Critique, History and International Law. UK: Cambridge Scholars Publishing, 2012.

CONNELL, Raewyn. A iminente revolução na teoria social. Rev. bras. Ci. Soc., São Paulo, v. 27, n. 80, p. 09-20, Out. 2012. Disponível em: http://www.scielo.br/scielo.php?script=sci arttext\&pid=S0102-

69092012000300001\&lng=en\&nrm=iso. Acesso em: 23 mai. 2020.

DUSSEL, Enrique. 1492: O encobrimento do Outro (o origem do "mito da modernidade"). Trad. Jaime A. Claesen. Petrópolis - RJ, Vozes, 1993.

FITZPATRICK, Peter. A mitologia na lei moderna. Coleção Díke. São Leopoldo: Editora Unisinos, 2009.

HERRERA FLORES, J. (Ed.). El vuelo de Anteo. Derechos humanos y crítica de la razón liberal. Bilbao: Desclée De Brouwer, 2000.

HERRERA FLORES, J. Teoria crítica dos direitos humanos. Os direitos humanos como produtos culturais. Rio de Janeiro: Lumen Juris, 2009a.

HERRERA FLORES, J. El proceso cultural: materiales para la creatividad humana. Sevilla: Aconcagua, 2005a.

HERRERA FLORES, J. Los derechos humanos como productos culturales. Crítica del humanismo abstracto. Madrid: Libros de la Catarata, 2005b.

MARINI, Ruy Mauro. Subdesenvolvimento e Revolução. Trad. Fernanda Correa Prado e Marina Machado Gouvêa. 3aㅡ edição. Florianópolis: Editora Insular, 2012.

MIGNOLO, Walter. Desobediência Epistêmica: retórica da modernidade, lógica da colonialidade e gramática da descolonialidade. Ediciones del Signo, Buenos Aires - Argentina, 2010. 
ROSILLO MARTÍNEZ, Alejandro. Derechos humanos desde el pensamiento latino-americano de liberación. 2011. 983f. Tese (Doctorado en Estudios Avanzados en Derechos Humanos) - Instituto de Derechos Humanos Bartolomé de Las Casas, Universidad Carlos III de Madrid. Madrid, 2011. Disponível em: https://e-archivo.uc3m.es/bitstream/handle/10016/12505/alejan\%20dro rosillo tesis.pdf?sequence=1. Acesso em: 20 nov. 2013. 